\title{
Highly Efficient Prodrugs: Design and Therapeutic Applications (A-Review)
}

\author{
ASHUTOSH PAL ${ }^{1 *}$ and BIMAL KRISHNA BANIK ${ }^{2 *}$ \\ ${ }^{1}$ Raja Peary Mohan College, West Bengal, India. \\ ${ }^{2}$ Department of Mathematics and Natural Sciences, College of Sciences and Human Studies, \\ Deanship of Research, Prince Mohammad Bin Fahd University, Al Khobar, Kingdom of Saudi Arabia. \\ *Corresonding author E-mail: ashupal33@gmail.com, bbanik@pmu.edu.sa \\ http://dx.doi.org/10.13005/ojc/360601
}

(Received: November 30, 2020; Accepted: December 20, 2020)

\begin{abstract}
Prodrug is a very powerful way for the improvement of biopharmaceutical, physicochemical, or pharmacokinetic possessions of pharmacologically dynamic mediators. Prodrug is a pharmacologically not an active compound, which can be converted into an active drug by biotransformation which is metabolic and such process the efficiency of drugs gets improved with specific target delivery. The conversion of a prodrug to drug may happen before concentration, after concentration, or at a precise part of the physique. This approach has many advantages over drug administration which is in our convention. In this review, different types of carriers, which can be used for prodrug synthesis are summarized. Examples of both marketed and investigational prodrugs from several promoieties are discussed not only for their advantages and uses but also their prospects. The purpose of this review is to introduce in detail the foundation behind the use of the prodrug methodology from past to present and at the same time to consider the possible consequences, which may evolve from insufficient initiation of prodrugs. Furthermore the concept of prodrug and the classifications of prodrugs will be discussed in this article and it is expected that this review will be helpful for medicinal chemists for their research in the upcoming days.
\end{abstract}

Keywords: Prodrug, Biopharmaceutical, Physicochemical, Pharmacokinetic, Metabolic biotransformation, Drug administration.

\section{INTRODUCTION}

Most of the drugs have undesirable physico-chemical properties that include good water solubility, unstable chemical nature, inadequate oral absorption, rapid metabolism, short half-life and moderate toxicity. It is noticeable that many potential drug compounds have been discontinued due to weak pharmacokinetic belongings and or otherwise unexpected poisonousness. Their healing power is enhanced by not only minimizing the unacceptable harmful properties but also by maintaining the good ones. An improvement is performed by biological, physical or chemical methods. The physical approach is dependable on a modification of the dosage. Chemical approach holds the most effective approach in enhancing drug selectivity. The aim of this approach is to design or develop new drugs or to do structural alterations creating prodrugs.

This is an Open Access article licensed under a Creative Commons license: Attribution 4.0 International (CC- BY). Published by Oriental Scientific Publishing Company @ 2018

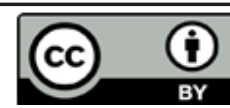


Adrian Albert first introduced the concept and term of prodrug ${ }^{1}$. Albert used the term "prodrug" or "proagent" as a pharmacologically indolent compound, which was transformed into an active medicine by a process of metabolic biotransformation. Subsequently, these types of compounds were denoted as the "latentiated drugs" and the procedure was named "drug latentiation". These molecules were also termed as "congeners" and bio reversible byproducts. However, 'prodrug' is the most acclaimed and most common name. The design of the prodrug is a principal amendment approach that is used to amend an error in a drug contender. Acetanilide was the first example of a prodrug. Cahn and Hepp introduced this molecule into the medical science in 1867 as an antipyretic agent. Acetanilide ${ }^{3}$ on activation with enzyme is hydroxylated to medicinally active acetaminophen (Fig. 1). This molecule is similar to paracetamol ${ }^{4}$ and methenamine ${ }^{5}$. Under acidic condition, methenamine degrades to formaldehyde and ammonia. It is used against urinary tract disorder. Another prodrug is aspirin $^{6}$, acetylsalicylic acid, fused by Felix Hoffman (Bayer, Germany). Dreser contributed this into medicine. Protonsil antibiotic ${ }^{1}$ is introduced more or less in the same period.<smiles>CC(=O)Nc1ccccc1</smiles>

Acetanilide

$\mathrm{CO}_{2} \mathrm{H}$<smiles>CCOc1ccccc1OC(C)=O</smiles>

Asprin<smiles>CCOc1ccc(NC(C)=O)cc1</smiles>

Phenacetin<smiles>CC(=O)Nc1ccc(O)cc1</smiles>

Paracetamol

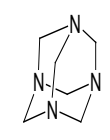

Methenamine

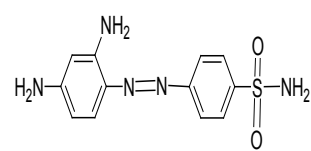

Prontosil
Fig. 1. Some earlier prodrugs

The concept of prodrug was identified during the structural modification of chloramphenicol ${ }^{7-9}$ to reduce the unpleasant taste and improve solubility in aqua. Two types of chloramphenicol prodrugs (Fig. 2) were synthesized. These were chloramphenicol sodiumsuccinate with good aquatic solubility and chloramphenicol palmitate with a suspension.
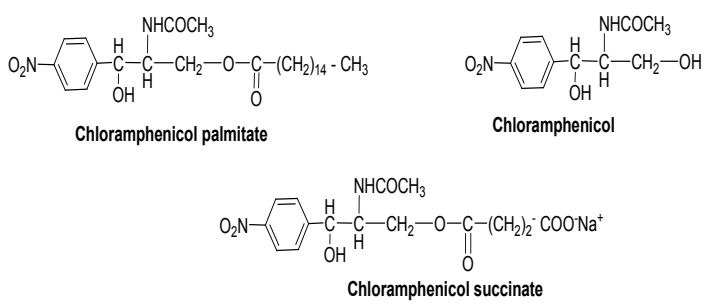

Fig. 2. Chloramphenicol and its prodrugs
During the early stage of science related to prodrugs, Roche revealed the function of the antitubercular drug isoniazid (hydrazide of isonicotinic acid) ${ }^{10,11}$. In some occasions, inadvertently developed prodrugs revealed a less tempting fact of the medicine under improvement. A case of this kind of drug was heroin (diacetylmorphine) (Fig. 3). This was marketed as a benign morphine to stop cough as well as to serve as remedy of cocaine and morphine addiction. Similarly, biological process of prodrug codeine generates morphine in vivo ${ }^{12}$. Bayer found that heroin can be rapidly metabolized into morphine in the body ${ }^{13,14}$.
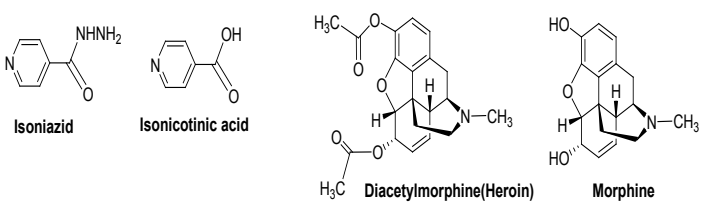

Fig. 3. Prodrugs of isonicotinic acid and morphine

Towards the closure of the nineteenth century, there has been a remarkable development in the usage of prodrugs in medicinal advancement. In 2009, about 15 percent of the 100 most popular low molecular heft medicines were reported to be prodrugs. Examples of chartbuster prodrugs are lisdexamfetamine dimesylate (Vyvanse) and the Lysine prodrug of the psychostimulant dextroamphetamine ${ }^{15}$. At present, about $10 \%$ of all international medicines are prodrugs. Moreover, nearly $15 \%$ and $33 \%$ of all new drugs permitted in 2001-2002 and 2008 were prodrugs. In 2008, 15\% of the 100 top selling medicines were prodrugs ${ }^{16-20}$. In 2008-2017, $12 \%$ of new molecular agents approved by the FDA were prodrugs ${ }^{21}$. These prodrugs got FDA approval in 2017-2018 (Fig. 4) 22-23. Deflazacort (Trade name is Emflaza) is hydrolyzed by esterase and forms 21-desacetyldeflazacort. Telotristat etiprate (Trade name is Xermelo) is hydrolyzed by carboxylesterase and forms Lp-778902. Valbenazine (Trade name is Ingrezza) activated by CYP 450 metabolism and forms mainly $\alpha$-dihydrotetrabenazine. Benznidazole (Trade name is Ingrezza) which on reduction by trypanosoma cruzinitroreductase forms various electrophilic metabolites. Secnidazole (Trade name is Solosec) which on reduction by bacterial nitroreductase forms its active metabolite. Latanoprostene (Trade name is Vyzulta) is hydrolyzed by corneal esterase to form latanoprost acid butanediol mononitrat. Fostamatinib (Trade name is Akynzeo) which on 
dephosphorylation by plasma phosphatase forms netupitant. Fosnetupitant (Trade name is Akynzeo) prodrug is an amalgamation of two medicines of fosnetupitant and palonosetron. Baloxavir marboxil (Trade name is Xofluza) is hydrolyzed by esterase and form S-033447.

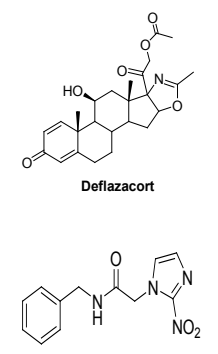

Benznidazole

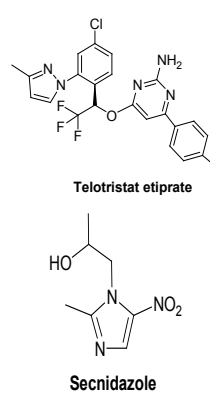

Secnidazole

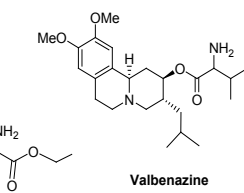

Latanoprostene $\overline{\bar{O}} \mathrm{H}$
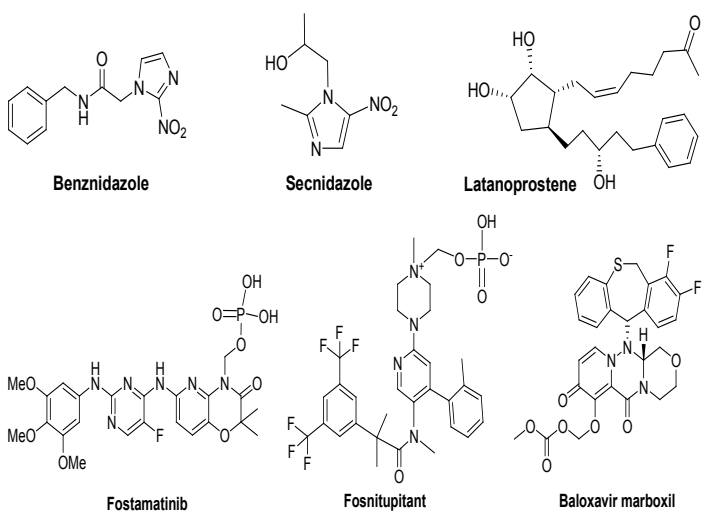

Fig. 4. FDA approval of prodrugs in 2017-2018

\section{Objectives of prodrug}

The objective of the prodrug ${ }^{24}$ is twofold.

First, it has to overcome numerous barriers to the efficacy of a drug's activity and secondly, it has to inhibit the side effects. The design of a prodrug is considered as a lead alteration that overcomes the error in a drug molecule. There are many explanations in front of us to apply a prodrug method in drug enterprise to deliver active medicine to the active sites. This avoids co-administering two medicines in order to improve medicinal effects and prevent side reactions ${ }^{25}$. The intaking of two medicines simultaneously may not be a clinically proven efficient process. Some commonly used drugs have these following properties:

1. Pharmaceutical: (a) Nonsufficient chemical stability: A medicine might be quickly absorbed and manifested as interactive before it stretches to the actual location. (b) Poor solubility: It is seen that some injectable drugs are insoluble in water. It may take a liter of brackish water to manage the effective dosage. However, the drugs may be safe, efficient and active. A water-soluble fragment can be bonded to the drug. This portion can be metabolically cleaved in the body after administration. (c) Offensive taste or odour: An effective medicine may have bad taste. It may generate irritation in stomach, and may cause pain. Under this situation, the structure of the molecule can be altered to stop these difficulties. However, the prodrug should be metabolized to the active medicine at the site.

2. Pharmacokinetics: (a) Weak oral absorption and presystemic metabolism: It is essential for a drug to be absorbed orally and it should reach to the target site in sufficient amount. However, some drugs may not have these properties. Under these situations, water soluble or lipid soluble medicines can be formulated. Once absorption is occurred, the water or lipid-soluble portion of the medicine can be removed by an enzymatic process or when the drugs reach at the site of the disease. (b) Short duration of action: Sometimes, it is desirable to maintain a low amount of medicine available over a long duration. The drug can be structurally modified so that it is metabolically transformed to the vigorous medicine gradually. (c) Pharmacodynamics: In its active composition, a drug can be toxic. It may have an advanced healing index if this can be given in a harmless or less toxic indolent form on condition that this produces the dynamic drug at the location of disease.

\section{Properties of Ideal Prodrugs}

If a prodrug has to be ideal, it must meet with a number of properties. These include: a) Pharmacological inertness in the absence of body fluids, b) Rapid ability to transform into the active form of the drug at the target organ, c) Ability to create nontoxic products and eliminate them spontaneously.

The common classification of prodrugs depends on the derivatization procedure and the nature of the carrier functional system attached to the drug (Fig. 5). Some prodrugs are discovered after these are isolated. Several tests of the metabolites obtained from these prodrugs indicate that the initiation of the drugs has happened. In many examples, a specific amendment in the drug molecule is performed based upon the accessibility of knowledge of metabolic conversions. For simplicity, prodrugs are divided into two classes: carrier-linked prodrugs and bio-precursors ${ }^{26,27}$. 


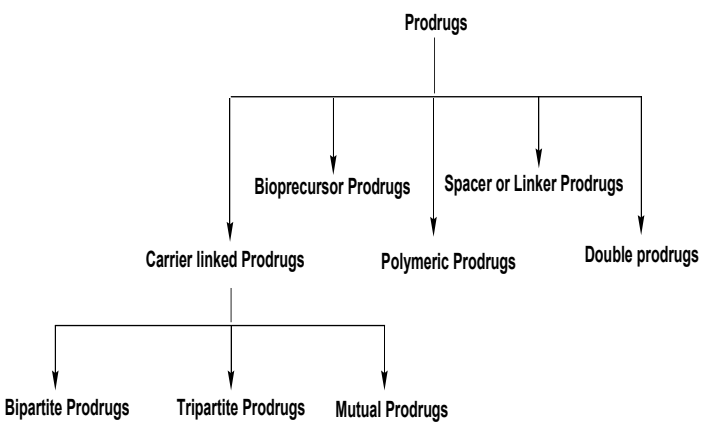

Fig. 5. Classification of Prodrugs

Carrier-linked prodrug: This comprises an active medicine connected to a transporter group and it could be eliminated easily. These groups include an unstable ester or a labile amide which can be hydrolyzed to generate the parent drug. In principle, the group removed must be an inactive, nontoxic, and non-immunogenic agent ${ }^{28,29}$.

A good carrier contains the following characteristics:

- $\quad$ This maintains the structure of the prodrug as long as it reaches the site of disease.

- It is not a stable but nontoxic molecule.

- This maintains the drug at the location of the action.

- It helps to release the drug by chemical or enzymatic action.

- It must bear biochemical inertness.

The carrier-linked prodrugs are divided into three subdivisions: (a) Bipartite Prodrugs, (b) Tripartite Prodrugs and (c) Mutual Prodrugs.

Bipartite prodrug: A bipartite prodrug has a transporter (promoiety) connected directly with the drug. These prodrugs alter the lipophilicity of the parent molecule. The active drug can be released by a chemical or enzymatic hydrolysis reaction, such as tolmetin-glycine prodrug ${ }^{30}$.

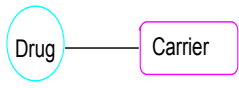<smiles>Cc1ccc(C(=O)c2cccn2CC(=O)NCO)cc1</smiles>

Fig. 6. Bipartite prodrug of tolmetin glycine

A few others popular bipartite prodrugs are prednisolone sodium phosphate, latanoprost, dipivefrin and etoposide phosphate ${ }^{31-33}$. Most of the carrier-attached prodrugs are bipartite. The phosphate ester prodrug of the prednisilone has higher water solubility compared to prednisolone. On the other hand, the phosphate ester compound is highly polar than the parent molecule. Latanoprost (Xalatan) is a useful drug against glaucoma. The highly lipophilic isopropyl ester prodrug can be hydrolysed by corneal esterases to produce the medicinally active, latanoprost (Figure 7).

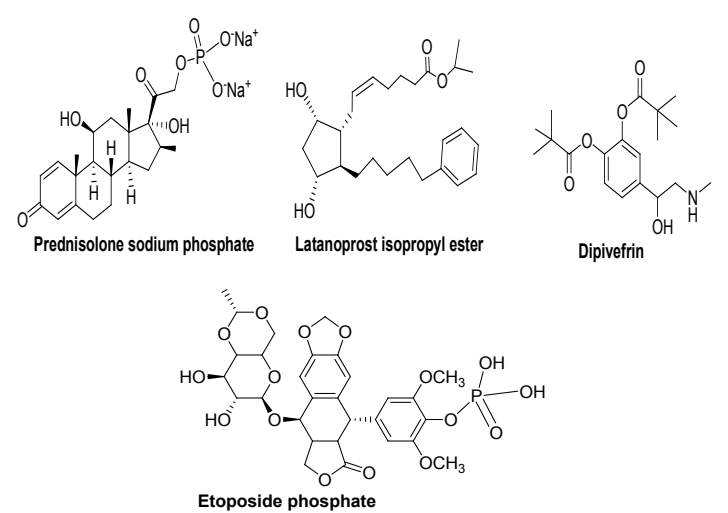

Fig. 7. Bipartite prodrugs of prednisolone sodium phosphate, latanoprost, dipivefrin, and etoposide phosphate

Tripartite prodrug: This uses a spacer or linker between the drug and a promoiety (Fig. 8). In some examples, the bipartite prodrug can be unstable because of the inherent nature of the drugpromoiety bonding. This problem can be overcome by synthesizing a tripartite prodrug ${ }^{34}$.

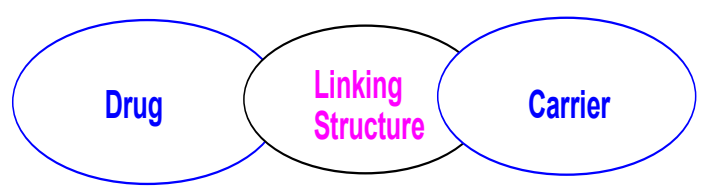

Fig. 8. The Drug and carrier are attached via a linker/spacer

Pivampicillin is an example of a tripartite prodrug. It consists of pivaloyloxymethyl ester, $\beta$-lactam, ampicillin. The prodrug has a $-\mathrm{CH}_{2}-$ linker to connect ampicillin and the pivalic acid. Pivampicillin has better biovailability than ampicillin because the ester group creates higher lipophilicity ${ }^{35}$ (Fig. 9). Bacampicillin is also an example of a tripartite prodrug.
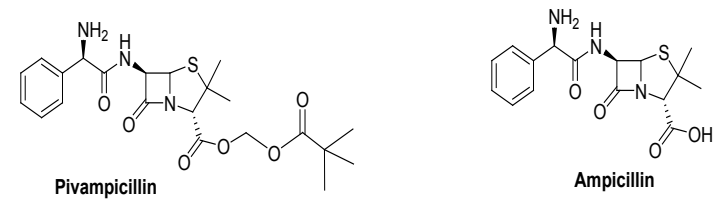

Fig. 9. Tripartite prodrugs of pivampicillin 


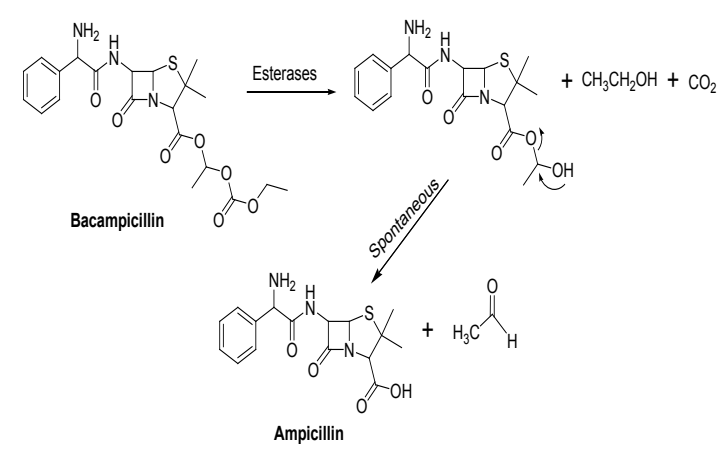

Fig. 10. Cleavage of tripartite prodrug bacampicillin

Mutual prodrug has two synergistic drugs linked to each other where one drug serves as the carrier for the other and opposite. Therefore, a mutual prodrug has two potent agents bound together in such a way that each acts as a promoiety for the other agent and vice versa.

An example of this idea is benorylate (Fig. 11). Aspirin is linked covalently to paracetamol through an ester linkage. This combination decreases gastric irritation but improves analgesic power ${ }^{36}$. Sultamicillin, on hydrolysis by esterase gives ampicillin and sulbactum and therefore, this is another example of this class of prodrugs.

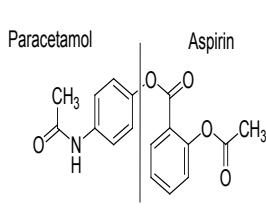

Benorylate / Benorilate

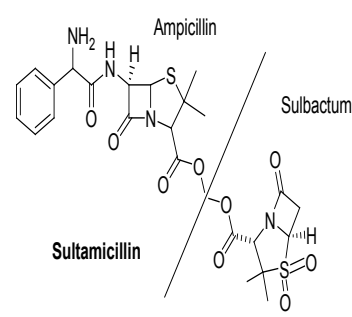

Fig. 11. Mutual prodrug of benorylate and sultamicillin

Bioprecursors prodrugs are metabolically activated by oxidation or reduction process rather than hydrolysis. If a drug contains a carboxylic acid group, the bioprecursor can be a primary amine that can be metabolized first to the aldehyde and then to the acid (Fig. 12). No carrier is present in this type of example, but the molecule must be metabolized to undergo functional group transformation ${ }^{37-39}$. Some examples include nabumetone (relafen), prontosil (Fig. 13), and cyclophosphamide prontosil (Figure 14) $)^{40-46}$.

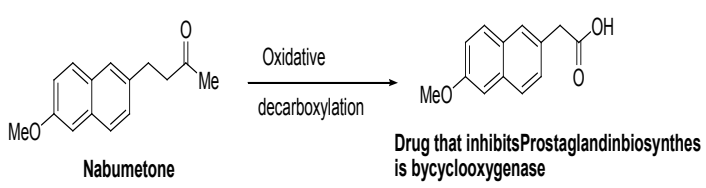

Fig. 12. Bioprecursor prodrug of relafen

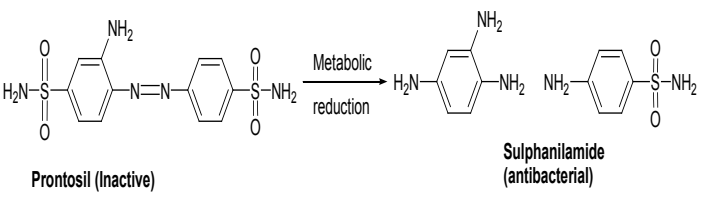

Fig. 13. Bioprecursor prodrug of prontosil<smiles>CC(C)[C@H](CCl)N(CCCl)P1(=O)NCCCO1</smiles>

Fig. 14. Bioprecursor prodrug of cyclophosphamide

Pralidoxime is very polar and therefore, it cannot overwhelm the blood-brain barrier effectively. A replacement of the pyridine group with dihydropyridine generates a prodrug and thus enhances lipophilicity to overwhelm the bloodbrain barrier. The dihydropyridine is converted to pyridinium to give the parent drug, pralidoxime through this oxidation process (Fig. 15). Pralidoxime (Protopam) is recommended as an antidote to treat poisoning by organophosphorus molecules.

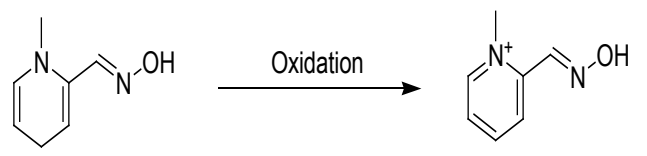

Dihydropyridine prodrug

Pralidoxime (Protopam)

Fig. 15. Bioprecursor prodrug of pradoxime activated by oxidative processes

Sulindac is an anti-inflammatory medicine used to treat acute and chronic inflammatory problems. This has a sulfoxide group. It is activated by the reduction mechanism by liver enzymes (Fig. 16). The sulfoxide is transformed to a thioether and the active metabolite generates. Since sulindac is a prodrug, the concentration of the active metabolite remains lower at the gastric mucosa. Therefore, the Gl side effects remain lowered compared to nonsteroidal anti-inflammatory drug, indomethacin.
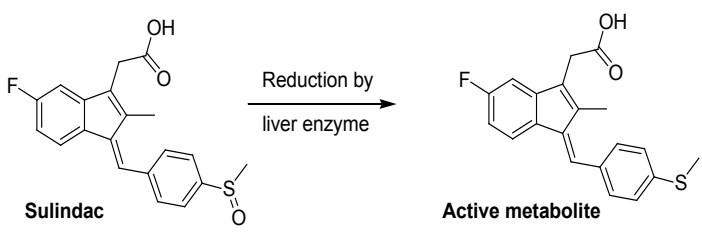

Fig. 16. Bioprecursor prodrug of sulindac activated by reduction processes

Polymeric Prodrug is recognized as macromolecular prodrug. The drug is disseminated or integrated into the natural or synthetic polymer system between the drug and polymer. An example 
of this procedure includes $\mathrm{p}$-phenylene diamine mustard (Fig. 17) ${ }^{47}$. This macromolecular conjugate is more efficient than the individual drugs or the mixture of compounds.

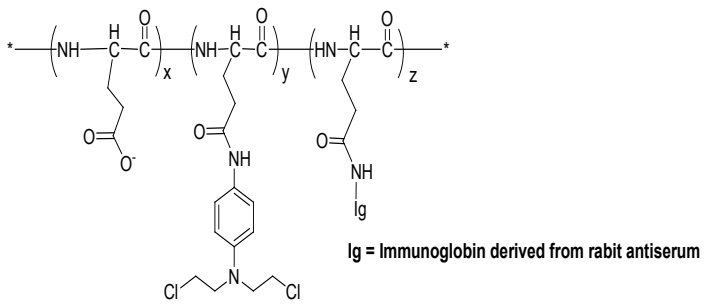

Fig. 17. p-Phenylene diamine mustard

Prodrugs of synthetic polymers with spacer arm: A linking of poly(methacrylate) with testosterone (Fig. 18) produces no androgenic effect. An insertion of a linker between the polymer and testosterone has effects like testosterone. This poly(methacrylate) chain was linked to the polymer due to an increase of water solubility.

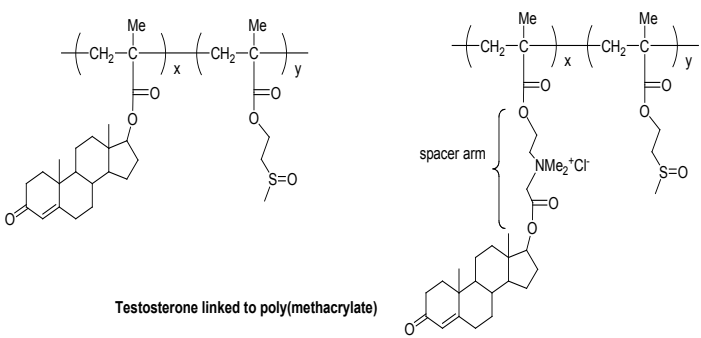

Fig. 18. Synthetic polymer prodrugs

Double prodrug is derivatized in a way like that enzymatic transformation occurs before it can sever to release the active drug. Specimen of such a concept includes benzodiazepines ${ }^{48}$, diesters of pilocarpic acid (Figure 19).<smiles>[R]c1ccc(N([R])C(=O)NC(N)=O)c(C(=O)c2ccccc2)c1</smiles>

A<smiles>CC(=O)N(O)CCCP(=O)(OCc1ccc(O)cc1)N(C)CCCCCl</smiles>
FR900098 Prodrug<smiles>CO/N=C(/C(=O)N[C@@H]1SCC(OC)=C1C(=O)OC(=O)OC(C)C)c1csc(N)n1</smiles>

Cefpodoxime Proxetil

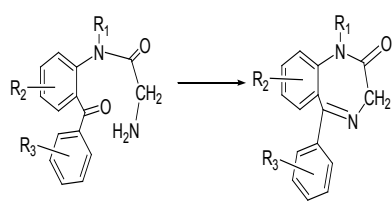

B

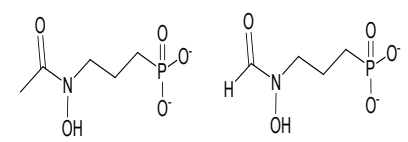

FR900098 Fosmidomycin (FSM)

Cefpodoxime

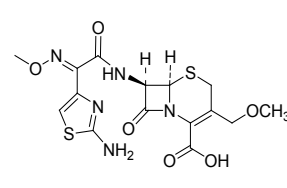

Fig. 19. Double prodrug of benzodiazepines and FR900098
Fosmidomycin and FR900098 are effective antimalarial agents. However, the application is limited because of reemergence of an active infection after treatment ${ }^{49}$. The weak bioavailability is due to weak lipophilicity ${ }^{50}$. Double prodrug $(A)$ of benzodiazepines can be converted to prodrug (B) due to the cleavage of amide functionality by aminopeptidase. Prodrug $B$ then participates in a cyclization process to the active drug (C). The rate of cyclization is controlled by the amino acid system and also by the nature of the substituent groups.

\section{Designing prodrugs using different functional groups as carrier}

Many functional groups can act as carriers for changing the structure of drugs. In reality, their choice depends on the functionality present on the parent drug. Some groups work fine to achieve moderately good drug candidates and these groups are esters, amides, carbamates, phosphates (Table 1).

Table 1: Designing prodrugs using different functional groups as carrier

\begin{tabular}{|c|c|c|}
\hline & Carriers & Name of parent drug \\
\hline 1 & Ester & $\begin{array}{l}\text { Palmarumycin, Etoposide, Diclofenac, } \\
\text { Acyclovir, MSX-2, Cf1743, Oleanoic acid, } \\
\text { Oridonin, Taxoids, Paclitaxel, Gambogic } \\
\text { acid, 6-Methoxy-2-naphthylacetic acid and } \\
\text { Quercetin }\end{array}$ \\
\hline 2 & Amides & $\begin{array}{l}\text { DW2282, Acyclovir, SB-3CT, NAP-G2-Asp, } \\
\text { PC190723 and Pyrazolo[3,4-d]pyrimides }\end{array}$ \\
\hline 3 & Phosphates & $\begin{array}{l}\alpha-6-C h l o r o-2-(\text { methylthio)-5-(napthalen-1- } \\
\text { yloxy)-1H-benzo[d], Propofol, Lopinavir, } \\
\text { Chalcone, SB-3CT and SNS-314 }\end{array}$ \\
\hline 4 & Carbamate & Cl-994 \\
\hline 5 & Carbonate & CHS8281 \\
\hline 6 & Ether & 10-Hydroxycamptothecin and Cadalene \\
\hline 7 & Imine & Amphotericin B \\
\hline
\end{tabular}

Medicinal uses of prodrugs to enhance patient satisfactoriness

Numerous medicin alapplications of prodrugs to overcome the limitation ${ }^{51-57}$ of general drugs include the followings: (i) improvement of taste; (ii) alteration of the physical from of the drug; (iii) improvement of the odor; (iv) less Gl irascibility; (v) decline in pain upon inoculation; (vi) increase of drug solubility and amalgamation in water; (vii) increase of chemical stability; (viii) improve of bioavailablity; (ix) prevent presystemic metabolism; (x) enhance extent of action; (xi) decrease in toxicity; (xii) locationspecific distribution. 


\section{Enhancement of taste}

Detrimental and bad palate can come on account of weak solubility and contact of medicine with taste receivers. It could be avoided by depressing the solubility of drug or prodrugs in spittle. For example, chloramphenicol is an unpleasant medicine and chloramphenicol palmitate, a cautiously soluble ester, is virtually unpalatable. This is because of its little aqueous solubility. Ethyl mercaptan has a low boiling point $\left(25^{\circ} \mathrm{C}\right)$ and a strongly felt foul odor. Other examples of prodrugs to reduce odor include clindamycin palmitate ester and sulfisoxazole diacetate ester (Figure 20).

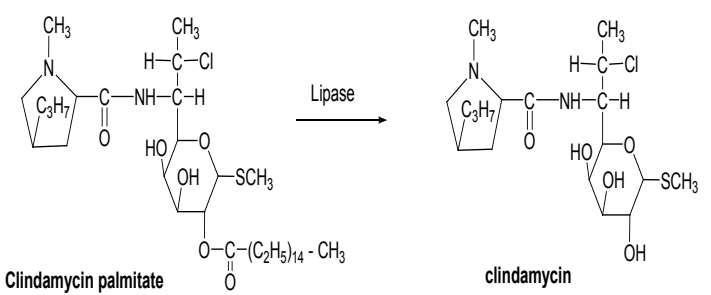

Fig. 20. Clindamycin prodrugs and their conversion to clindamycin

\section{Changes in physical form of drugs}

To make some liquid drugs into solid dosage form is difficult to achieve, particularly if the dose is high. These liquid drugs can be converted into solid prodrugs via creation of symmetrical molecules, which have better propensity to crystallize, as example, esters of trichloroethanol.

\section{Improvement odor}

The ethyl mercaptan has a low boiling point of $25^{\circ} \mathrm{C}$ and has a pungent odor. Diethyl dithioisophthalate, a prodrug variation of thioethanol, has a much higher boiling point. It is also much less odorless (Figure 21).

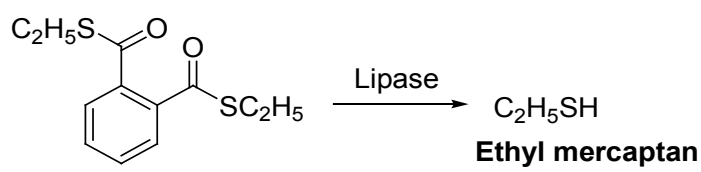

Fig. 21. Diethyl dithioisophthalate, a prodrug of ethyl mercaptan

\section{Decline in GI irritation}

Numerous drugs may irritate and harm the gastrointestinal mucosa. This is possible because of increased production of acid, such as aspirin, a prodrug of salicylic acid is helpful to diminish gastric annoyance.

\section{Lessening of agony on injection}

Ache occurred by intramuscular injection is because of the feebly acidic nature or meager aqueous solubility of certain medicines. For instance, IM injection of antibiotics clindamycin and anti-convulsant phenytoin is painful because of meagre solubility. Therefore, prodrugs are prepared. 2'-Phosphate ester of clindamycin and the hydantoic ester prodrug of phenytoin (fosphenytoin) are two examples.

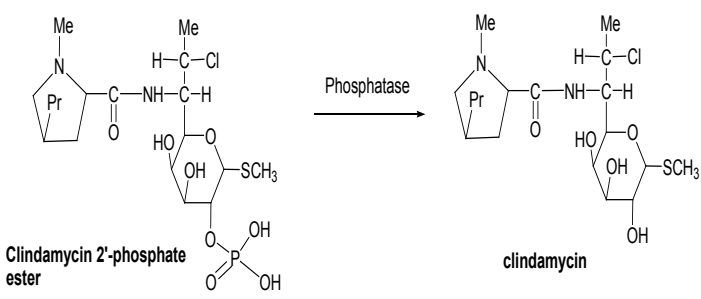

Fig. 22. Clindamycin-2'-phosphate ester cleaves to clindamycin by phosphatase

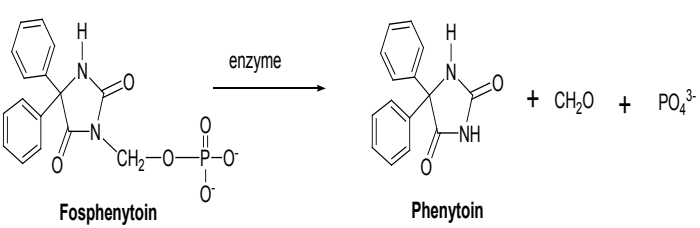

Fig. 23. Fosphenytoin to phenytoin generation by phosphatase enzyme

\section{Enhancement of drug solubility and dissolution} rate

An investigation performed on the best 200 oral drugs in Japan, UK, United States, and Spain found that on an average $37 \%$ of drugs had water solubility of less than $0.1 \mathrm{mg} / \mathrm{mL}^{58}$. The aqueous soluble prodrug of methyl prednisolone is methylprednisolone sodium succinate. However, the in vitro stability of this molecule is weak because of intramolecular catalysis. Therefore, it is used as a lyopolized power that is reconstituted with water ${ }^{59}$. Another example is given to explain this topic further. The aqueous solubility of betamethasone is $58 \mu \mathrm{g} /$ $\mathrm{mL}$ at $25^{\circ} \mathrm{C}$. The solubility of the corresponding disodium phosphate ester is about $100 \mathrm{mg} / \mathrm{mL}$. Thus, the salt in water is 1500 -fold more soluble than the parent compound. Acetylated sulfonamide group is capable of enhancing the aqueous solubility of the sodium salt of the COX-2 inhibitor parecoxib $\sim 300$-fold. Phosphorylation method is successfully applied to improve the water solubility in the design of fospropofol, a prodrug of propofol ${ }^{60,61}$, fosaprepitant and fosnetupitant ${ }^{62-67}$. In another approach, gabapentin enacarbil is designed to improve the bioavailability of gabapentin by aiming intestinal and sodium-dependent multivitamin transporters. 


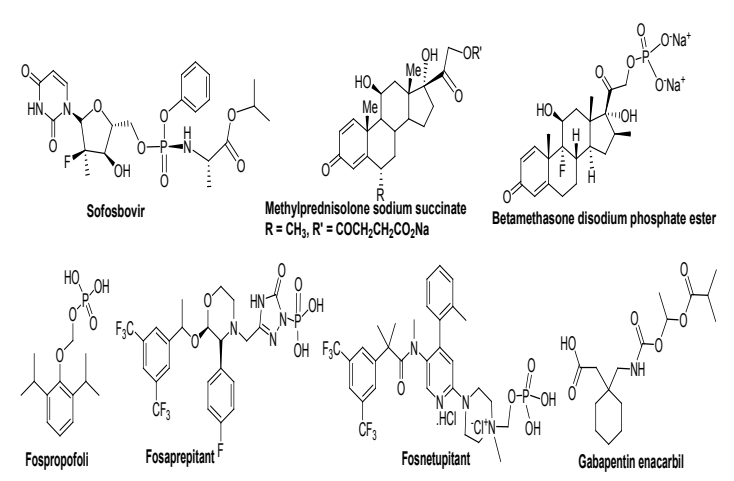

Fig. 24. Examples of prodrugs with enhanced hydrophility

Glycerol ester has superior aqueous solubility of about $0.55 \mu \mathrm{mol} / \mathrm{mL}$ compared to its parent drug $\left(0.0034 \mu \mathrm{mol} / \mathrm{mL}\right.$ of water solubility) ${ }^{68}$ (Figure 25$)$.<smiles>O=C(O)Cc1ccccc1Nc1c(Cl)cccc1Cl</smiles><smiles>O=C(CO)COC(=O)COC(=O)OCc1ccccc1Nc1c(Cl)cccc1Cl</smiles>

Fig. 25. Diclofenac and its glycerol ester prodrug

DW2282, (S)-1-[1-(4-aminobenzoyl)-2,3dihydro-1H-indol-6-sulphonyl]-4-phenyl-imidazolidin-2one is an anticancer molecule with low water solubility $(0.024 \mathrm{mg} / \mathrm{mL})$ and high gastrointestinal toxicity ${ }^{69}$. However, the amide prodrug (Fig. 26) is soluble in water $(0.86 \mathrm{mg} / \mathrm{mL})$. It has a good bioavailability also ${ }^{70}$.

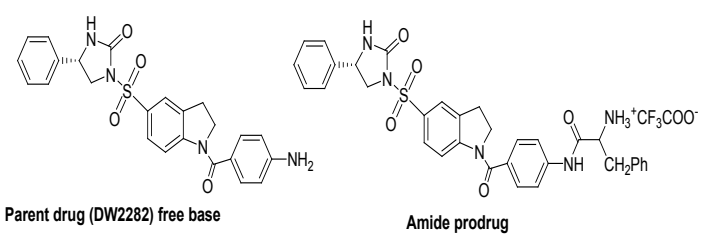

Fig. 26. Drug DW2282 and its amide prodrug

Table 2: Prodrugs for improved aqueous solubility

\begin{tabular}{cc}
\hline Parent drugs & Prodrugs with enhanced hydrophilicity \\
\hline Propofol & Fospropofol \\
Enalaprilat & Enalapril \\
Ampicillin & Pivampicillin \\
Adefovir & Adefovir dipivoxil \\
Tenofovir & Tenofovir disoproxil \\
Miproxifene & Miproxifene phosphate \\
Amprenavir & Fosamprenavir \\
9-Beta-D-arabinosyl- & Fludarabine \\
2-fluoroadenine & Fosphenytoin \\
Phenytoin & Fosfluconazole \\
Fluconazole & Phosphonooxymethyl propofol \\
Propofol & Propofol phosphate \\
Propofol & Irinotecan \\
SN-38 & Valacyclovir \\
Aciclovir & Valganciclovir \\
Ganciclovir &
\end{tabular}

\section{Enrichment of chemical constancy}

Chemical constancy is an important part of every therapeutic agent. As stated, the prodrug method relies upon the alteration of the functionality accountable for the unstable nature. This method also targets to change the corporeal characteristics of the drug that results in the fall of interaction between the drug and the media. For example, propranolol (Fig. 27, $R=R^{\prime}=H$ ) is applied as antihypertensive drug. Because of first-pass exclusion of the drug, an oral dose has lower bioavailability than the dose given by intravenous injection. The major metabolites of this drug are propranolol O-glucuronide (Fig. 27, $\mathrm{R}=\mathrm{H}$, OR' glucuronide), p-hydroxy propranolol (Fig. 27, $\mathrm{R}=\mathrm{OH}, \mathrm{R}^{\prime}=\mathrm{H}$ ) and its O-glucuronide (Fig. 27, $\mathrm{R}$ $=\mathrm{OH}, \mathrm{OR}^{\prime}$ glucuronide). The hemisuccinate ester of propranolol (Fig. 27, $\mathrm{R}=\mathrm{OH}, \mathrm{R}^{\prime}=\mathrm{COCH}_{2} \mathrm{CH}_{2} \mathrm{COOH}$ ) was synthesized to inhibit glucuronide synthesis. Through an oral administration of propranolol hemisuccinate, the plasma levels of propranolol can be increased eight times higher than the case in which when propranololis used ${ }^{71}$.
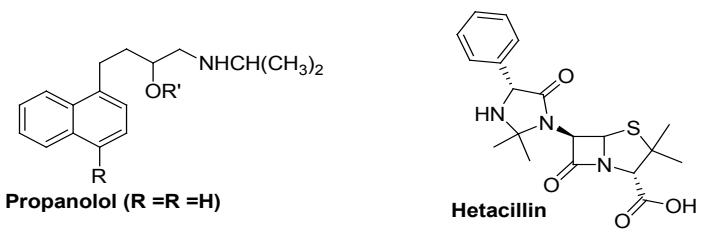

Fig. 27. Prodrug, propranolol and hetacillin

Hetacillin belongs to a beta-lactam antibiotic family. This prodrug has no antibacterial activity, but it can produce acetone in the human body to generate the antibiotic ampicillin. Stopping the auto-aminolysis, which is possible because of $\mathrm{NH}_{2}$ group to attach $\beta$-lactam structure of the other molecule, ampicillin generates polymeric species. By producing hetacillin, a prodrug of ampicillin ties up the amino functionality and therefore, it inhibits auto-aminolysis.
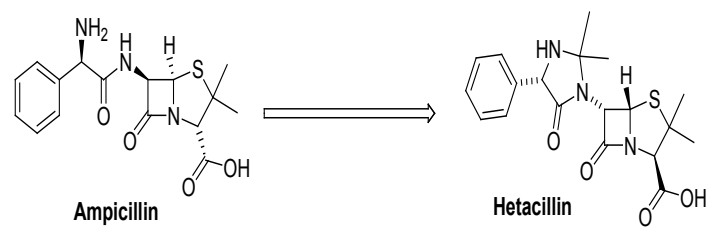

Fig. 28. Hetacillin prodrug

Enhancement of bioavailablity

Numerous medicines such as vitamins, natural purine and pyrimidine nucleosides, dopamine, ampicillin and carbenicillin, phenytoin and gitoxin suffer with weak gastrointestinal absorption. The 
principal reason of the weak immersion of these compounds is due to their polar nature, weak lipophilicity, and metabolic tendency.

The absorption of vitamins is improved by a derivatization process of the thiolate ion to form fat-soluble prodrug. Dopamine is made medically helpful through its precursor L-Dopa. L-Dopa is a polar molecule. This is conveyed through L-amino acid active transport process and rejuvenates dopamine through a decarboxylation route ${ }^{72}$.<smiles>NC(Cc1ccc(O)c(O)c1)C(=O)O[Na]</smiles><smiles>NCCc1ccc(O)c(O)c1</smiles>

Fig. 29. L-DOPA prodrug conversion

L-Valyl zanamivir, a prodrug of zanamivir is formulated (Fig. 30). The uptake of this prodrug is higher through the PepT transporters. This process improves its absorption through the oral route ${ }^{73}$.

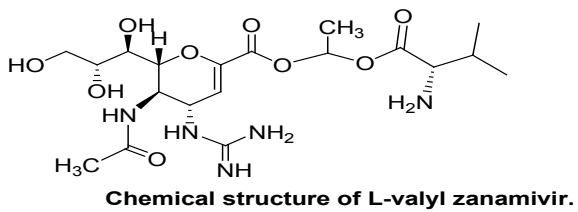

Fig. 30. L-Valyl zanamivir, a prodrug of zanamivir

Curcumin has a weak bioavailability because of its unstable nature under physiological conditions. This eliminates from the body due to poor absorption and rapid metabolism. To overcome the problems, diverse methods have been designed to improve the bioavailability of curcumin. A conjugation of small endogenous compounds (diacids, amino acids and glucose) is performed.

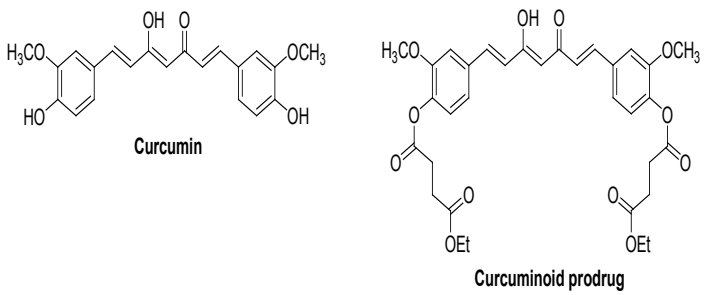

Fig. 31. Structure of Curcumin and its succinate prodrugs

\section{Prevention of presystemic metabolism}

A successful medicine should go through metabolizing organs (liver and gastrointestinal system) prior to reaching the transmission. An oxidative $\mathrm{N}$ - and $\mathrm{O}-$ dealkylation method, ester hydrolysis, and peptide breakage are feasible for the metabolism of many drugs. The first group of drugs is quickly degraded by the acid present in the stomach. The second group of drugs is degraded due to the enzymatic process in the gastrointestinal mucosa and liver. The metabolism of a drug is stopped if a certain functionality is protected by derivatization. Another manipulation of the drug is to modify the physicochemical characteristics. For example, naltrexone (medicine for opioid addiction) is absorbed quickly in the digestive tract and therefore, goes through presystemic metabolism.
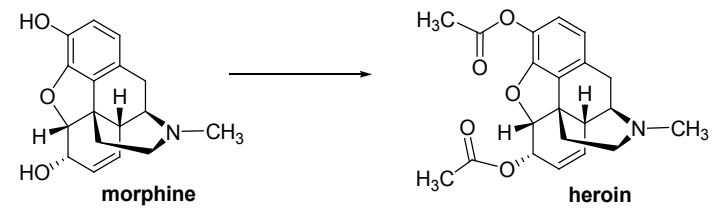

Fig. 32. Morphine converted to prodrug heroin

\section{Prolongation duration of action}

Medicines those are short half-life period are given frequent dosing with standard dosage to maintain sufficient plasma concentration and the activity period of a drug can be maintained by the prodrug. Testosterone propionate, estradiol propionate, and fluphenazine deaconate are some prodrugs and their active drugs are testosterone, estradiol, and fluphenazine respectively.

Prolonged release medicines are crucial in the treatment of psychose. Patients of this group require medication for a longer period of time. Haloperidol is a sedative and tranquilizer and its peak plasma level is seen between 2 and $6 \mathrm{~h}$ after intake. The activity of the prodrug haloperidol deconate lasts for a month ${ }^{74}$ if given intramuscularly.

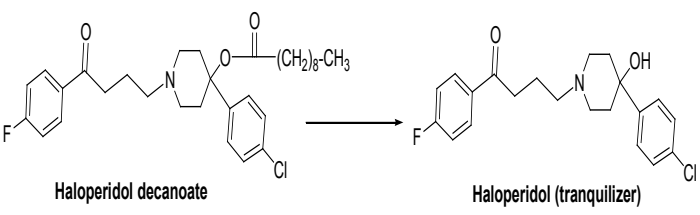

Fig. 33. Haloperidol deconate is an orally active prolonged release drug

The activity of antipsychotic medicine lasts for 6-8 h, whereas the activity of fluphenazine remains for a month.

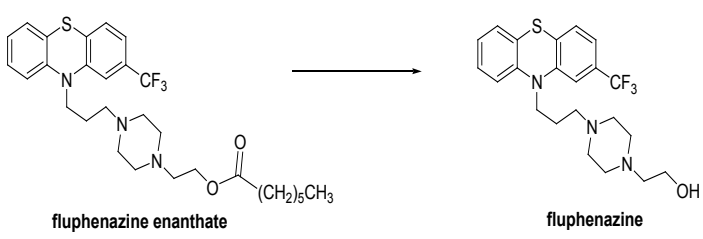

Fig. 34. Fluphenazine enanthate prolonged release drug 


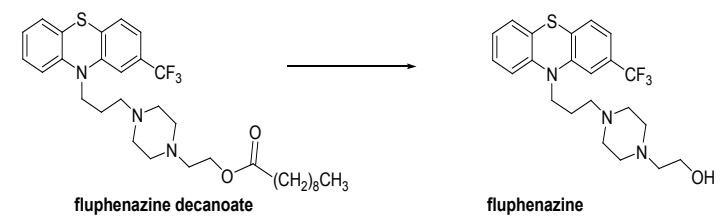

Fig. 35. Fluphenazine deconate prolonged release drug

Anti-inflammatory drug, tolmetin sodium is converted to the glycine conjugate to increase the activity and extends the peak concentration to approximately 9 hours. This can happen for the weak hydrolysis of the prodrug amide bond ${ }^{75}$.

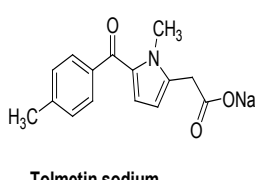

duration of activity $\sim 1 \mathrm{~h}$

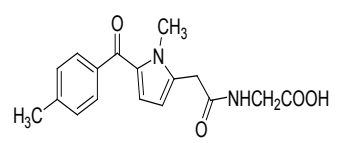

Tolmetin Glycine conjugate duration of activity $\sim 9 \mathrm{~h}$
Fig. 36. Prolonged release drugs of tolmetin glycine

\section{Reduction in toxicity}

The prodrug should have minimum or no toxicity. Epinephrine, an eye medicine, has numerous ocular and systemic side effects. The prodrug dipivaloylepinephrine is more active than epinephrine ${ }^{76}$ with an improved profile. Doxorubicin is an anticancer drug. However, the use of this medicine requires caution because of its cardiotoxicity. There was a critical requirement to design medicines to increase doxorubicin availability in cancer cells and decrease its function in the cardiac system ${ }^{77}$. Toward the goal, a galactoside prodrug linked to doxorubicin through a carbamate group was developed (Figure 37).

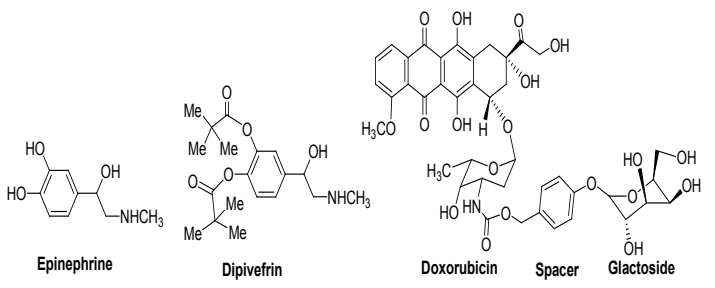

Fig. 37. Epinephrine, Dipivefrin and Doxorubicin with galactoside linker

Sulindac doesn't cause gastric irritation and has much fewer side effects than indomethacin. Ibuterol is a diisobutyrate ester of terbutaline used against glaucoma. This prodrug is 100 times more active, remains active for a longer time and does not cause local and systemic toxicity.
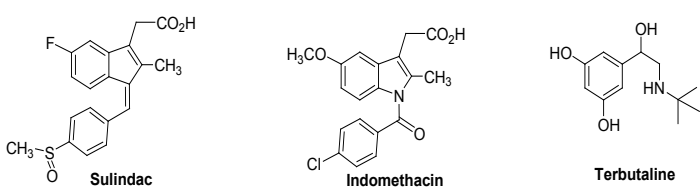

Fig. 38. Prodrugs reduced toxicity

\section{Site-specific delivery}

The targeting of medicines to the body organ by conversion to a prodrug works well if the physicochemical characteristics of the original drug and prodrug match well for the target site. The medicines go to different sites of the body. This limitation is fixed by targeting the medicine to the actual part of the problems by prodrug design. The prodrug is then transformed to the active form of the drug in the target tissue. This process may occur by specific enzymes or by acidity. Tumor cells have large amounts of phosphate and amidases than normal cells. Therefore, a cytotoxic prodrug is directed to the tumor cells if these enzymes are crucial to activate the prodrug. Diethylstilbestrol diphosphate $e^{78,79}$ is formulated for site-specific delivery of diethylstilbestrol to prostatic cancer patients. Oxyphenisatin is a bowel sterilant when given rectally. The acetylated prodrug oxyphenistatin acetate is administered orally. Finally, it is degraded at the intestines to oxyphenisatin.

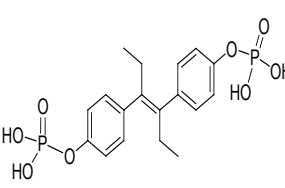

Diethylstilbestrol diphosphate

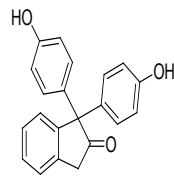

Oxyphenisatin

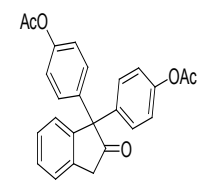

Noloc
Fig. 39. Site specific prodrugs

\section{Structures, uses and applications of a few prodrugs} that receive FDA approval during 2008-2018 ${ }^{80-89}$ :

(1) Fesoterodine Fumarate (Trade name is Toviaz) prodrug is hydrolyzed by esterase to get its active drug 5-hydroxymethyl tolterodine. It is a muscarinic receptor antagonist is recommended to treat an overactive bladder muscles with problems of urinary frequency, urgency, and incontinence.

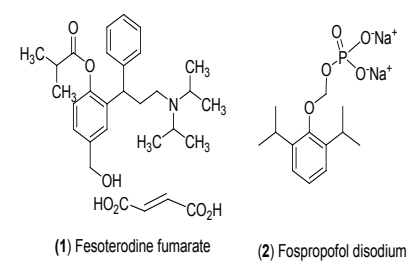

(2)

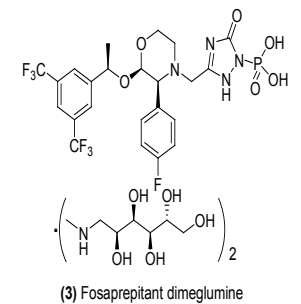

Fospropofol disodium (Trade name is Lusedra) prodrug is converted by alkaline phosphatase to get its active drug propofol. Fospropofol often used as disodium injection is an intravenous 
sedativehypnotic agent recommended for monitored anesthesia care sedation in adult patients undergoing diagnostic or therapeutic procedure such as endoscopy.

(3) Fosaprepitant dimeglumine (Trade name is Emend) prodrug is activated by dephosphorylation by phosphatase to get its active drug aprepitant. Fosaprepitant dimeglumine is designed for chemotherapy regimens in combination with other antiemetics drugs to prevent of acute and delayed nausea and vomiting after receiving certain cancer chemotherapy treatment.

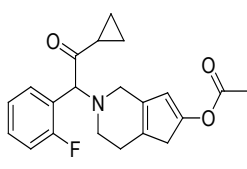

(4) Prasugrel

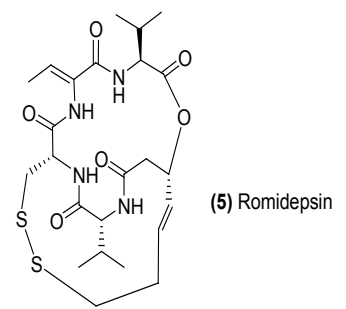

(4) Prasugrel (Trade name is Effient) prodrug is hydrolyzed by (1) esterase and (2) CYP450 metabolism to get its active drug R-138727. Prasugrel is used with aspirin by patients to prevent blood clots with acute coronary syndrome with heart disease who undergo a certain heart procedure and in people with certain disorders of the heart or blood vessels.

(5) Romidepsin Prasugrel (Trade name is Istodax) prodrug is activated by intracellular glutathione to get its active metabolite with free thiol group. Romidepsin is a HDAC inhibitor and its injection is recommended to treat cutaneous T-cell lymphoma in people who have had at least one prior systematic therapy and already been treated with at least one other medication.

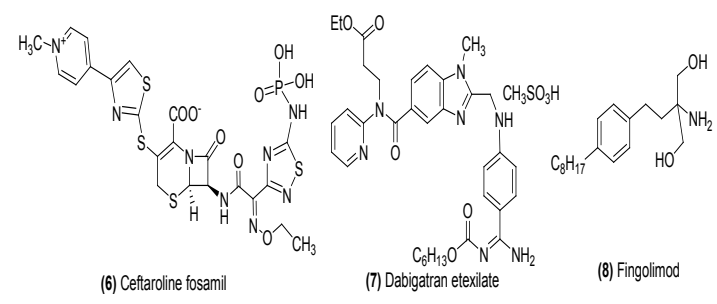

(6) Ceftaroline fosamil (Trade name is Teflaro) prodrug is activated by plasma phosphatase to get its active drug ceftaroline. Ceftaroline fosamil is a fifth-generation cephalosporin antibiotic used with broad spectrum of bactericidal property. Food and Drug Administration was approved the drug for the cure of community-acquired bacterial pneumonia and acute bacterial skin and skin structure infections.

(7) Dabigatran etexilate (Trade name is Pradaxa) prodrug is hydrolyzed by esterase to get its active drug dabigatran. Dabigatran is an anticoagulant drug used to treat deep vein thrombosis and blood clots in the lungs.

(8) Fingolimod (Trade name is Gilenya) Phosphorylation by sphingosine kinase to get its active drug fingolimod-phosphate. This drug is mostly recommended to treat relapsing multiple sclerosis. This is not a cure for MS but it helps by preventing immune system cells from attacking the nerves in brain and spinal cord.

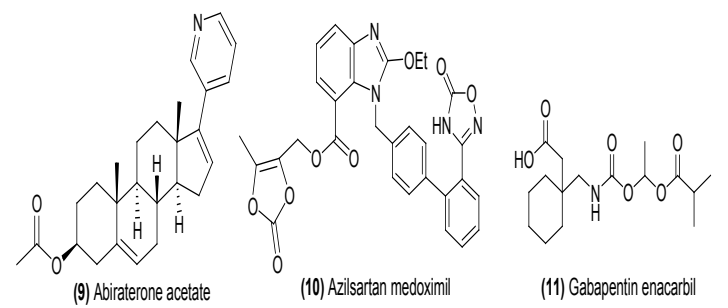

(9) Abiraterone acetate (Trade name is Zytiga) prodrug is hydrolyzed by (1) esterase and (2) Metabolism CYP3A4 and SULT2A1 to get its active drug abiraterone sulfate and $\mathrm{N}$-oxide abiraterone sulfate. Abiraterone acetate is use in combination with prednisone for prostate cancer that has spread to other parts of the body, the treatment of metastatic castration-resistant prostate cancer. This drug is helpful for the patient who has received chemotherapy with doacetaxel.

(10) Azilsartan medoximil (Trade name is Edarbi) prodrug is hydrolyzed by esterase during absorption and form its active drug azilsartan. Azilsartan is recommended for the treatment of hypertension to lowering high blood pressure and help to prevent strokes, heart attacks, and kidney problems.

(11) Gabapentin enacarbil (Trade name is Horizant) is hydrolyzed by esterase and form its active drug Gabapentin. Gabapentin enacarbil is an anticonvulsant and analgesic drug recommended to treat moderate-tosevere primary Restless Legs Syndrome which occurs due to neurologic disorder. 


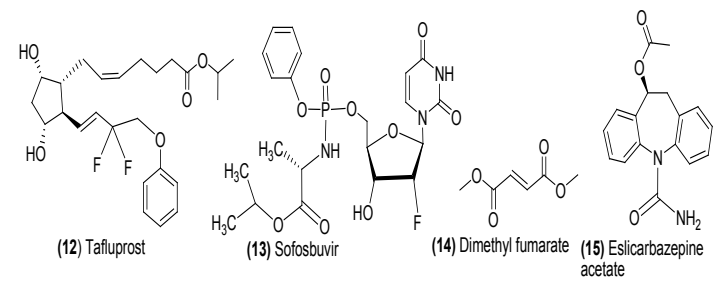

(12) Tafluprost (Trade name is Zioptan) is hydrolyzed by esterase and form its active drug Tafluprost acid. Tafluprost ophthalmic is used to reduce raised pressure within the eye.

(13) Sofosbuvir (Trade name is Sovaldi) prodrug which is intracellular metabolized by (1) cathepsina carboxyl esterase 1 (2) histidine triade nucleotide-binding protein 1 and (3) uridine monophosphatecytidine monophosphate kinase and converted into its active form GS461203. Sofosbuvir is used in combination with other antiviral medications (ribavirin, peginterferon, daclatasvir) to treat chronic (longlasting) hepatitis $C$, a viral infection of the liver.

(14) Dimethyl fumarate (Trade name is Tecfidera) is hydrolyzed by esterase and form its active drug monomethyl fumarate. Dimethyl fumarate is used with various forms of multiple sclerosis.

(15) Eslicarbazepine acetate (Trade name is Aptiom) is hydrolyzed during first pass metabolism and form its active drug eslicarbazepine. Eslicarbazepine is a new anti-epileptic drug recommended alone or in combination with other medications to treat seizure disease. It works as anticonvulsants.

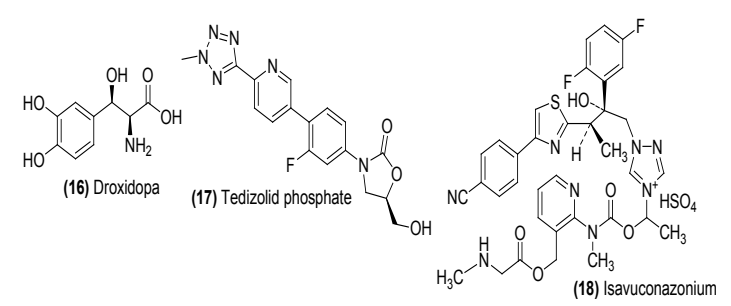

(16) Droxidopa (Trade name is Northera) converted its active drug to form Norepinephrine by decarboxylation with L-aromatic-amino-acid decarboxylase. Droxidopa is used to treat low blood pressure caused by a specific medical condition (neurogenic orthostatic hypotension).

(17) Tedizolid phosphate (Trade name is Northera) get its active drug Tedizolid depho-sphorylation by plasma phosphatase. Tedizolid is recommended for the treatment of acute bacterial skin infections caused by certain susceptible bacteria, including Staphylococcus aureus.

(18) Isavuconazonium sulfate (Trade name is Cresemba) is hydrolyzed by (1) esterase and (2) intramolecular cyclization leading to $\mathrm{N}$-dealkylation to get its active drug isavuconazole. Isavuconazonium is recommended to treat certain serious fungal infections invasive aspergillosis and invasive mucormycosis in adults.<smiles>CCOC(=O)C(C)CCc1ccc(-c2ccccc2)cc1</smiles><smiles></smiles><smiles>CCCCCCCCCCCC(=O)OCN1C(=O)CCc2ccc(OCCCCN3CCN(c4cccc(Cl)c4Cl)CC3)cc21</smiles>

(19) Sacubitril (Trade name is Entresto) which is de-ethylation by liver carboxylesterase 1 to get its active form LBQ657. Sacubitril and valsartan combinations are used to prevent chronic heart failure. Sacubitril and valsartan reduce the risk of death from chronic heart failure with reduced ejection fraction.

(20) Uridine triacetate (Trade name is Xuriden) which is deacetylation by esterase to get its active form uridine. Uridine triacetate is used for the emergency treatment of patient who have either received too much of chemotherapy medications.

(21) Aripiprazole lauroxil (Trade name is Aristada) is hydrolyzed by (1) esterase and (2) Nonenzymatic hydrolysis to get its active drug aripiprazole. Aripiprazole lauroxil is used in the treatment of schizophrenia.

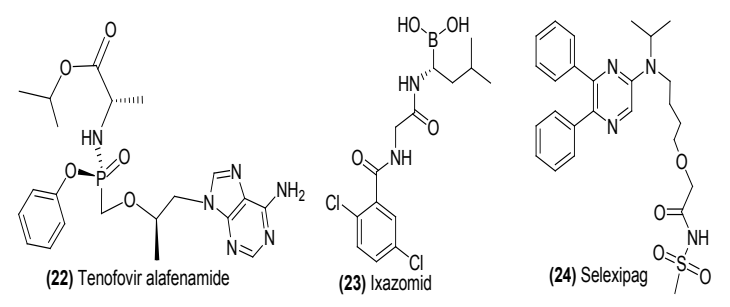

(22) Tenofovir alafenamide (Trade name is Genvoya, Odefsey, Descovy) is hydrolyzed by lysosomal protective protein or liver carboxylesterase 1 to get its active form tenofovir. Tenofovir alafenamide is recommended to treat chronic hepatitis $B$ 
infection. Chronic hepatitis infection may cause liver damage (cirrhosis) and liver cancer.

(23) Ixazomid citrate (Trade name is Ninlaro) which got rapid hydrolysis post administration and form its active drug Active boronic form. Ixazomib is recommended to treat multiple myeloma a type of white blood cell cancer, in combination chemotherapy with lenalidomide and dexamethasone.

(24) Selexipag (Trade name is Uptravi) is hydrolysed by carboxylesterase to form ACT-333679 (MRE-269). Selexipag is recommended to control pulmonary arterial hypertension.

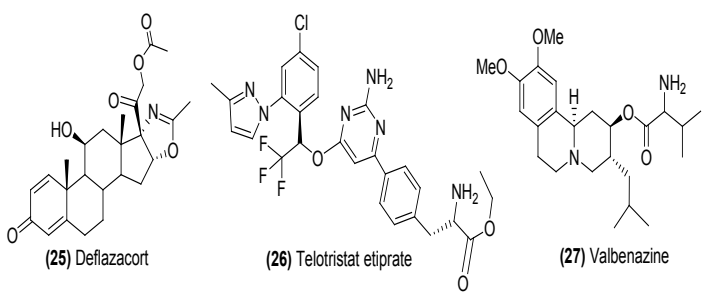

(25) Deflazacort (Trade name is Emflaza) is hydrolyzed by esterase and form 21desacetyldeflazacort. Deflazacort ia a corticosteroids class of drug widely used to treat systemic lupus erythematosus, autoimmune hepatitis, sarcoidosis, rheumatoid arthritis, allergies and asthma.

(26) Telotristat etiprate (Trade name is Xermelo) is hydrolyzed by carboxylesterase and form Lp-778902. Xermelo is recommended for the treatment of carcinoid syndrome diarrhoea in combination with somatostatin analogue.

(27) Valbenazine (Trade name is Ingrezza) activated by CYP450 metabolism and form mainly $\alpha$-dihydrotetrabenazine. Valbenazine is recommended for tardive dyskinesia. This disease is a neurological disorder and used to treat involuntary movements of the face, tongue, or other body parts.

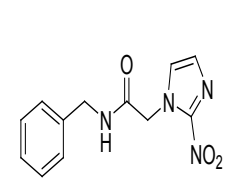

(28) Benznidazole<smiles>Cc1cnc(C)n1CC(C)O</smiles>

(29) Secnidazole

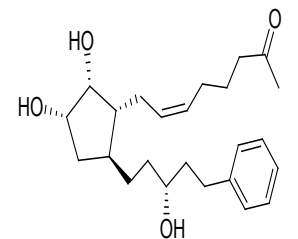

(30) Latanoprostene
(28) Benznidazole (Trade name is Ingrezza) which on reduction by trypanosoma cruzinitroreductase to form various electrophilic metabolites. Benznidazole is recommended to treat a certain parasitic infection.

(29) Secnidazole (Trade name is Solosec) which on reduction by bacterial nitroreductase to form its active metabolite. This drug is used to treat specific type of vaginal infection. This drug is not work for common viral infections such as cold, flu etc.

(30) Latanoprostene (Trade name is Vyzulta) is hydrolyzed by corneal esterase to form latanoprost acid butanediol mononitrat. Latanoprostene is a prostaglandin analogs recommended to treat glaucoma and ocular hypertension.

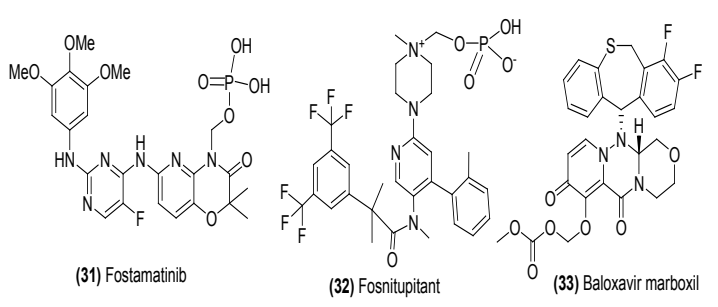

(31) Fostamatinib (Trade name is Akynzeo) which on dephosphorylation by plasma phosphatase to form netupitant. Fostamatinib is used to treat adults with low platelet count because of chronic immune thrombocytopenia.

(32) Fosnetupitant (Trade name is Akynzeo) prodrug is a combination of two medications: fosnetupitant and palonosetron and is used to prevent nausea and vomiting caused by cancer drug.

(33) Baloxavir marboxil (Trade name is Xofluza) is hydrolyzed by esterase and form S-033447. Baloxavir marboxil is used to against the influenza.

\section{CONCLUSION}

In this review, the chemistry, biology, and medicinal effects of prodrugs are discussed. The classifications of prodrugs are discussed. The benefits of the prodrug approach have been demonstrated widely to overcome the undesirable pharmacokinetic properties and to optimize therapeutic efficacy without losing the benefits of 
the drugs. This method has the potential to become a hot and practical clinical topic in medicinal science. On the basis of several examples of prodrugs and their functions, many other studies directed to this subject should be forthcoming.

\section{ACKNOWLEDGEMENT}

BKB is grateful to Prince Mohammad Bin Fahd University for encouragement.

\section{Conflicts of Interests}

None

\section{REFERENCES}

1. Albert, A. Nature., 1958, 182, 421-422.

2. Li, X.; Hu, M. Oral Bioavailability: Basic Principles, Advanced Concepts, and Applications., August 2011.

3. Bertolini, A.; Ferrari, A.; Ottani, A.; Guerzoni, S.; Tacchi, R.; Leone, S. CNS Drug. Rev., 2006, 12(3-4), 250-75.

4. Testa, B. Curr. Opin. Chem. Biol., 2009, 13(3), 338-44.

5. Rautio, J. Prodrug strategies in drug design, in Prodrugs and Targeted Delivery: Towards Better ADME, December 2010.

6. Properties (Rautio J ed) pp 1-30, Wiley-VCH Verlag GmbH \& Co. KGaA, Weinheim; 2010.

7. Burke, A. S.; FitzGerald, Garret A. Goodman and Gilman's the pharmacological basis of therapeutics. 11 ed. New York: McGraw-Hill; 2006.

8. Stella, V; Borchardt, R.; Hageman, M.; Oliyai, R.; Maag, H.; Tilley, J. Prodrugs: challenges and Rewards Published by AAPS Press and Springer., 2007, 1-2.

9. Glazko, A. J.; Carnes, H. E.; Kazenko, A.; Wolf, L. M.; Reutner, T.F. Antibiot Annu., 1957, 5, 792-802.

10. Li, X.; Oral Bioavailability: Basic Principles, Advanced Concepts, and Applications.

11. Bentley R. J. Ind. Microbiol Biotechnol., 2009, 36, 775-786.

12. Harper, N. J. Prog. Drug Res. 1962, 4, 221-294

13. Rautio, J.; Hanna, K.; Tycho H. Nature., 2008, 7, 255-268.

14. Inturrisi, C.E.; Schultz, M.; Shin, S.; Umans. J. G.; Angel, L.; Simon, E. J. Life Sciences., 1983, 33, 773-776.

15. Stella, V. J. Springer, New York, 2006, 221-242.
16. Smith and Williams; Introduction to the Principles of Drug Design and Action; Taylor and Francis Group, USA., 4, 216-230.

17. Stella, V. J.; Burchardt, R.T.; Hageman, M. J.; Oliyai, R.; Maah, H.; Tilley, J. W. Springer, New York, 2007, 1.

18. Stella, V. J. Exp. Opin. Ther. Patents., 2004, 14, 277-280.

19. Stella, V. J, Springer, New York., 2006, 221-242.

20. Stella, V. J. Drugs., 1985, 29, 455.

21. Rautio, J.; Meanwell, N. A.; Di, L. Nat Rev Drug Discov., 2018, 17(8), 559-587.

22. Rautio, J.; Kärkkäinen, J.; Sloan, K. B. Eur J Pharm Sci., 2017, 109, 146-161.

23. Najjar, A.; Najjar, A.; Karaman, R. Molecules., 2019, 16, 1-5.

24. Rautio, J.; Kumpulainen, H.; Heimbach, T.; Oliyai, R.; Oh, D.; Järvinen, T.; Savolainen, J. Nat. Rev. Drug Discov., 2008, 7, 255-270.

25. Stella, V. J.; Charman W.N.; and Naringrekar V. H. Drugs., 1985, 29, 455-473.

26. Harper, N. J. Med. Chem., 1959, 1, 467.

27. Wermuth, C. G. In Drug Metabolism and Drug Design: Quo Vadis, Briot M., Cautreels, W.; Roncussi, R. (Eds), Sanofi-Clin-Midy., Montpellier, 1983, 253.

28. Jana, S.; Mandlekar, S.; Marathe, P. Curr. Med. Chem., 2010, 17(32), 3874-908.

29. Stella, V. ACS Symposium Series. : American Chemical Society., 1975, 14 1-115.

30. Persico, F. J.; Pritchard, J. F.; Fisher, M. C.; Yorgey, K.; Wong. S.; Carson, J. J Pharmacol Exp Ther., 1988, 247(3), 889-96.

31. Inturrisi, C. E.; Schultz, M.; Shin, S.; Umans, J. G.; Angel, L.; Simon, E. J. Life Sciences., 1983, 33, 773-776. 
32. Stella, V. J. Springer, New York., 2006, 221-242.

33. Smith and Williams; Introduction to the Principles of Drug Design and Action; Taylor and Francis Group, USA; 2006, 4, 216-230.

34. Jornada, D.; dos Santos Fernandes, G.; Chiba, D.; de Melo, T.; dos Santos, J.; Chung, M. Molecules., 2016, 21, 42

35. Stella, V. J.; Burchardt, R.T.; Hageman, M.J.; Oliyai, R.; Maah, H.; and Tilley, J.W. Springer, New York., 2007, 1.

36. Stella, V. J. Exp. Opin. Ther. Patents., 2004, 14, 277-280.

37. Huttunen, K. M.; Raunio, H.; Rautio, J. Pharmacol Rev., 2011, 63, 750-771.

38. Silverman, R. The Organic Chemistry of Drug Design and Drug Action. $2^{\text {nd }}$ edn., Elsevier Academic Press, Burlington., 2004.

39. Srinivas, N. R. Eur J Drug Metab Pharmacokinet, 2011, 36, 49-59.

40. Das, N.; Dhanawat, M.; Dash, B.; Nagarwal, R. C.; Shrivastava, S. K. Eur J Pharm Sci., 2010, 41, 571-588.

41. Graf, N.; Lippard, S. J. L. Adv Drug Deliv Rev., 2012, 64, 993-1004.

42. Kokil, G. R.; Rewatkar, P. V. Mini Rev Med Chem., 2010, 10, 1316-1330.

43. Rautio, J. Kumpulainen, H.; Heimbach, T.; Oliyai, R.; Oh, D.; Järvinen, T.; Savolainen, J. Nat Rev Drug Discov., 2008, 7, 255-270.

44. Shi, Y.; Liu, S-A.; Kerwood, D. J.; Goodisman, J.; Dabrowiak, J. C. J Inorg Biochem., 2012, 107, 6-14.

45. Testa, B. Curr Opin Chem Biol., 2009, 13, 338-344.

46. Wu, K-M. Pharmaceuticals., 2009, 2, 77-81.

47. Rowland, G. F.; O’Neil, G. J.; Davies, D.A.L. Nature., 1975, 255, 487.

48. Siegel, R. A.; Kapoor, M.; Cheryala, N.; Georg, G. I.; Cloyd, C. J. Epilepsy \& Behavior., 2015, 49, 347-350.

49. Lell, B.; Ruangweerayut, R.; Wiesner, J.; Missinou, M. A.; Schindler, A.; Baranek, T.; Hintz, M.; Hutchinson, D.; Jomaa, H.;
Kremsner, P. G. Antimicrobial agents and chemotherapy., 2003, 47(2), 735-738.

50. McKenney, E.S.; Sargent, M.; Khan, H.; Uh, E.; Jackson, E. R. PLOS ONE., 2012, 7(10), e38167.

51. Beaumont, K.; Webster, R.; Gardner, I.; Dack, K. Curr. Drug Metab., 2003, 4, 461-485.

52. Ettmayer, P.; Amidon, G. L.; Clement, B.; Testa, B. J. Med. Chem., 2004, 47, 2393-2404.

53. Jarvinen, T.; Rautio, J.; Masson, M.; Loftsson, T. in Drug Discovery Handbook (ed. Gad, S.) 733796 (John Wiley \& Sons, Hoboken, 2005).

54. Stella, V. J. Expert Opin. Ther. Pat., 2004, 14, 277-280.

55. Testa, B. Biochem. Pharmacol., 2004, 68, 2097-2106.

56. Stella, V. Prodrugs: Challenges and Rewards (AAPS Press/Springer, New York, 2007). An excellent book of all aspects of prodrugs.

57. Stella, V. J.; Nti-Addae, K. W. Adv. Drug Deliv. Rev., 2007, 59, 677-694.

58. Takagi, T.; Ramachandran, C.; Bermejo, M.; Yamashita, S.; Yu, L.X.; Amidon, G.L. Mol. Pharm., 2006, 3, 631-643.

59. Silverman, R. B.; Holladay, M.W. in The Organic Chemistry of Drug Design and Drug Action (Third Edition)., 2014, 423-468

60. Mc Comb.; Bowers, G.N.; and Posen, S. Plenum Press, New York., 1979, 986-987.

61. Schywalsky, M. J. Anaesthesiol., 2003, 20, 182-190.

62. Stella, V. J.; Zygmunt, J. J.; Georg, I. G.; Muhammed, S. US19980131385., 2005.

63. Stella, V.J.; Nti-Addae, K.W. Adv. Drug. Deliv. Rev., 2007, 59, 677-694.

64. Sauer, R.; Maurinsh, J.; Reith, U.; Fulle, F.; Klotz, K.N.; Muller, C. E. J. Med. Chem., 2000, 43, 440-448.

65. Safadi, M.; Oliyai, R.; Stella, V.J. Pharm. Res., 1993, 10, 1350-1355.

66. Kristiina, M.; Jarkko, R. Bentham Science Publishers., 2011.

67. Schmidt, F. Bio. org. Med. Chem., 2003, 11, 2277-2283. 
68. Lobo, S.; Li, H.; Farhan, N.; Yan, G. Drug Dev Ind Pharm., 2014, 40, 425-432.

69. Flores-ramos, M.; Ibarra-Velarde, F.; Hernandez-campos, A.; Vera-Montenegro, Y.; Jung-cook, H.; CantoAlarcon, G.J.; del Rivero, L.M.; Castillo, R. Bioorg Med Chem Lett., 2014, 24, 5814-5817.

70. Kumpulainen H.; Jarvinen T.; Mannila A.; Leppanen J.; Nevalainen T.; Mantyla A.; Vepsalainen J.; Rautio J. Eur J Pharm Sci., 2008, 34, 110-117.

71. Garceau, Y.; Davis, I.; Hasegawa, J. J. Pharm. Sci., 1978, 67, 1360-63.

72. Yang, C.Y. Pharm. Res., 1999, 16, 1331-1343.

73. Dahan, A.; Khamis, M.; Agbaria, R. \& Karaman, R. Expert opinion on drug delivery., 2012, 9(8), 1001-13.

74. Deberdt, R.; Elens, P.; Berghmans, W.; Heykants, J.; Woestenborghs, R.; Driesens, F.; Reyntjens, A.; Van Wjingaarden, I. Acta Psychiat. Scand., 1980, 62, 356-363.

75. Persico, F. J.; Pritchard, J. F.; Fischer, M. C.; Yorgey, K.; Wong, S.; Karson, J. J. Pharm. Sci., 1988, 247, 889-890.

76. Hussain, M. A.; Koval, C. A.; Myers, M. J.; Shami, E. J.; Shiefter, E. J. Pharm. Sci., 1987, $76,356$.
77. Platel, D.; Bonoron-Adele, S.; Dix, R. K.; Robert, J. British journal of cancer., 1999, 81(1), 24-27.

78. Harper, N. J. J. Med. Pharm. Chem., 1959, 1, 467-500.

79. Brandes, D.; Bourne, G.H. Lancet., 1955, 1, 481-87.

80. Hughes, B. Nat Rev Drug Discov., 2009, 8(2), 93-96.

81. Hughes, B. Nat Rev Drug Discov., 2010, 9(2), 89-92.

82. Mullard, A. Nat Rev Drug Discov., 2011, 10(2), 82-85.

83. Mullard, A. Nat Rev Drug Discov., 2012, 11(2), 91-94.

84. Mullard, A. Nat Rev Drug Discov., 2013, 12(2), 87-90.

85. Mullard, A. Nat Rev Drug Discov., 2014, 13(2), 85-89.

86. Mullard, A. Nat Rev Drug Discov., 2015, 14(2), 77-81.

87. Mullard, A. Nat Rev Drug Discov., 2016, 15(2), 73-76.

88. Mullard A. Nat Rev Drug Discov., 2017, 16(2), 73-76.

89. Najjar, A.; Najjar, A.; Karaman, R. Molecules., 2020, 25, 884-895. 